\title{
Novas espécies e nota sobre Cerambycidae (Coleoptera) neotropicais da coleção Arriagada, Santiago, Chile
}

\author{
Maria Helena M. Galileo ${ }^{1,3}$ \& Ubirajara R. Martins ${ }^{2,3}$
}

\begin{abstract}
'Museu de Ciências Naturais, Fundação Zoobotânica do Rio Grande do Sul. Caixa Postal 1188, 90001-970 Porto Alegre-RS, Brasil. ${ }^{2}$ Museu de Zoologia, Universidade de São Paulo. Caixa Postal 42494, 04218-970 São Paulo-SP, Brasil

${ }^{3}$ Bolsista do CNPq.
\end{abstract}

\begin{abstract}
New species and note on Cerambycidae (Coleoptera) of Arriagada's collection, Santiago, Chile. Notes on a melanic form of Trachyderes (T.) cingulatus Klug, 1825 (Trachiderini) are provided and new taxa are described: Eburiini, Pantomallus titinga sp. nov. from Bolivia (La Paz, Santa Cruz); Elaphidionini, Stizocera asyka sp. nov. from Paraguay (Presidente Hayes); Ibidionini, Cycnidolon immaculatum sp. nov., from Bolivia (La Paz); Desmiphorini, Ischnoleomimus arriagadai sp. nov. from Paraguay (Paraguari); Ceiupaba bella sp. nov., from French Guiana, Ecuador (Pichincha) and Bolivia (La Paz); Euestola obliqua sp. nov. from Paraguay (Caazapá).
\end{abstract}

Keywords. Cerambycinae; Lamiinae; Neotropical; new species; taxonomy.

Resumo. Notas sobre uma forma melânica de Trachyderes (T.) cingulatus Klug, 1825 (Trachiderini) e descrição de novos táxons: Eburini, Pantomallus titinga sp. nov. da Bolivia (La Paz, Santa Cruz); Elaphidionini, Stizocera asyka sp. nov. do Paraguai (Presidente Hayes); Ibidionini, Cycnidolon immaculatum sp. nov., da Bolívia (La Paz); Desmiphorini, Ischnoleomimus arriagadai sp. nov. do Paraguai (Paraguari); Ceiupaba bella sp. nov., da Guiana Francesa, Equador (Pichincha) e Bolívia (La Paz); Euestola obliqua sp. nov. e Paraguay (Caazapá).

Palavras-chave. Cerambycinae; Lamiinae; Neotropical; novas espécies; taxonomia.

Recebemos para estudo parte dos Cerambycidae da coleção Gerardo Arriagada de Santiago, Chile (GASC), que reúne, principalmente, exemplares da Bolívia, Paraguai e Argentina. Acrescentamos também outros exemplares pertencentes ao Museu de Ciências Naturais, Fundação Zoobotânica do Rio Grande do Sul, Porto Alegre (MCNZ); Muséum National d'Histoire Naturelle, Paris (MNHN); Museu Nacional, Universidade Federal do Rio de Janeiro, Rio de Janeiro (MNRJ) e Museu de Zoologia, Universidade de São Paulo (MZSP).

O objetivo é descrever novos táxons em Cerambycinae nas tribos Eburiini, Elaphidionini, Ibidionini e em Lamiinae, na tribo Desmiphorini. Comentamos também uma forma melânica de Trachyderes (T.) cingulatus Klug, 1825, ocorrente no Brasil, Pará.

\section{Cerambycinae}

Eburiini

\section{Pantomallus titinga sp. nov.}

(Fig. 4)

Colorido geral amarelado ou laranja-amarelado. Borda anterior do pronoto, tubérculos pronotais, tubérculos laterais do protórax, friso sutural dos élitros, perímetro das manchas ebúrneas dos élitros, espinhos elitrais e ápices dos fêmures, escurecidos. Cada élitro com quatro faixas ebúrneas: duas na base, a externa apenas mais longa do que a interna; duas centrais, não-contíguas, a externa ultrapassa a interna anterior e posteriormente. Cabeça, protórax e élitros com pubescência branco-amarelada, muito fina. Pontos dos élitros evidentes (25x) sob a pilosidade.

Lobos oculares superiores com seis fileiras de omatídios. Antenas (fêmea) atingem a extremidade dos élitros na ponta do antenômero IX. Escapo atinge a borda anterior do pronoto. Flagelômeros basais (fêmea) com pêlos amarelados, curtos e densos. Espinhos laterais do protórax acuminados. Extremidades dos meso- e metafêmures com aba apical interna aguçada.

Dimensões em mm, fêmea. Comprimento do protórax, 2,13,3; maior largura do protórax, 3,1-4,9 comprimento do élitro, 11,5-17,5; largura umeral, 3,7-6,2.

Holótipo fêmea procedente da BOLÍVIA, Santa Cruz: Santa Cruz (600 m), 4.XI.1960, Zischka col. (MZSP). Parátipos: fêmea, BOLÍVIA, La Paz: Guanay (Uyapi), X.1993, (sem nome do coletor) (MCNZ); fêmea, idem, (Aserradero), 15.X.1996, G. Castillo col. (GASC).

Discussão. Espécies sul-americanas do gênero Pantomallus foram revistas por MARTINS (1999). MARTINS \& Galileo (2002) acrescentaram P. martinezi descrita da Colômbia. Pantomallus titinga sp. nov., assemelha-se mais a P. tristis (Blanchard, 1843) e a P. piruatinga Martins, 1997.

Distingue-se de $P$. tristis pelas manchas ebúrneas, centrais, dos élitros, não-contíguas e a externa ultrapassa, em comprimento, a interna anterior e posteriormente; pelos espinhos laterais do protórax acuminados e pela sutura elitral enegrecida. Em P. tristis, as manchas centrais são contíguas ou muito próximas e a interna e a externa iniciam-se no mesmo 
nível; nas fêmeas, os espinhos laterais do protórax não são aguçados e a sutura elitral é concolor.

Difere de P. piruatinga pelo colorido geral amarelado; pelo escurecimento da borda anterior do protórax; pelas manchas ebúrneas, basais, dos élitros mais estreitas e separadas; pelas manchas centrais lineares e separadas; pela pontuação elitral mais fina e pela sutura elitral enegrecida. Em P. piruatinga, o colorido geral é avermelhado; a borda anterior do pronoto não é escurecida; as manchas ebúrneas basais são muito curtas e as centrais contíguas e de aspecto mais elíptico; pontuação elitral mais densa e sutura elitral concolor.

Etimologia. Tupi, titinga $=$ mancha branca, alusivo às manchas elitrais.

\section{Elaphidionini \\ Stizocera asyka sp. nov.} (Fig. 1)

Colorido corporal preto; flagelômeros e tarsos avermelhados; cada élitro com mancha amarelada, adiante do meio, oblíqua em sentido descendente da margem para a sutura, que não toca a margem e aproxima-se da sutura.

Lobos oculares superiores com quatro fileiras de omatídios, tão distantes entre si quanto mais do que o dobro da largura de um lobo. Escapo subcilíndrico. Antenômeros III-V com espinho apical interno; o espinho do antenômero III desenvolvido e o dos demais antenômeros com comprimento gradualmente decrescente. Antenômero III com $1 / 3$ do comprimento do antenômero IV. Protórax tão longo quanto largo, bem abaulado no meio dos lados com a constrição basal bem pronunciada. Pronoto com duas gibosidades ao nível do terço anterior; partes laterais do protórax com pubescência mais densa. Prosterno com pubescência na metade posterior. Escutelo revestido por pubescência amarelada. Élitros com setas longas e esbranquiçadas; extremidades obliquamente truncadas com espinho curto no lado externo. Fêmures pedunculados e clavados; ápice dos meso- e metafêmures com abas apicais projetadas. Metatíbias carenadas.

Dimensões em mm, macho. Comprimento do protórax, 2,7; maior largura do protórax, 2,7; comprimento do élitro, 8,5; largura umeral, 3,0.

Holótipo macho proveniente do PARAGUAI, Presidente Hayes: Monte Lindo, XII.1993, sem nome do coletor (MZSP).

Discussão. Stizocera asyka sp. nov., pela chave de MARTINS \& NAPP (1983), é discriminada no item 14 por apresentar mancha de tegumento amarelado antes do meio dos élitros juntamente com S. meinerti Aurivillius, 1900 e S. spinicornis (Fairmaire, 1864). Distingue-se amplamente das duas espécies pelo protórax preto e bem abaulado nos lados; pelas manchas de pubescência ântero-laterais do protórax; pela presença de pubescência na metade posterior do prosterno e pelas extremidades elitrais. Em S. meinerti e S. spinicornis o protórax é avermelhado, mais longo do que largo e tem lados subparalelos; as partes ântero-laterais e o prosterno não têm pubescência; as extremidades elitrais em $S$. spinicornis são obliquamente truncadas e em S. meinerti o ângulo marginal possui espinho longo.

Etimologia. Tupi, asyka = cortado, alusivo ao colorido elitral interrompido por faixa amarelada.

\section{Ibidionini \\ Cycnidolon immaculatum sp. nov.}

(Fig. 6)

Cabeça preta revestida por pilosidade serícea, esbranquiçada. Olhos divididos; lobos oculares superiores com três fileiras de omatídios. Antenas com o escapo castanhoavermelhado, antenômero III vermelho-alaranjado e os antenômeros seguintes mais amarelados. Antenômero III engrossado na metade apical e carenado no pedúnculo; antenômero IV não-engrossado (macho). Protórax preto. Partes laterais do protórax pubescentes na metade posterior. Pronoto com três tubérculos: dois látero-anteriores e um central mais desenvolvido do que os demais. Élitros preto-avermelhados sem manchas ou faixas claras; metade anterior sem pubescência serícea e metade apical inteiramente recoberta por pubescência, menos nos espinhos apicais externos, que são longos e amarelados. Pernas castanho-avermelhadas.

Dimensões em mm, macho. Comprimento do protórax, 1,8; maior largura do protórax, 1,2; comprimento do élitro, 5,3; largura umeral,1,6.

Holótipo macho, procedente da BOLÍVIA, La Paz: Uyapi (Huanoy), coletado em X.1993, sem nome do coletor (MZSP).

Discussão. Assemelha-se mais a C. minutum Martins, 1960 pelos olhos divididos, ápices dos élitros uniespinhosos, antenômero III engrossado e pedunculado nas antenas dos machos. Difere de C. minutum pela ausência de manchas mais claras na metade anterior dos élitros; partes laterais do protórax pubescentes na metade posterior; disco pronotal com três tubérculos. Em C. minutum, os élitros têm mancha triangular, amarelada, na metade anterior glabra dos élitros; partes láteroposteriores do protórax sem pubescência serícea e pronoto sem tubérculos.

\section{Trachyderini \\ Trachyderes (Trachyderes) cingulatus Klug, 1825} (Fig. 2)

Trachyderes cingulatus Klug, 1825: 456.

Trachyderes (Trachyderes) cingulatus; Monné, 1994:95.

Trachyderes reichei Dupont, 1836: 31, est. 155.

Trachyderes reichei peruvianus Tippmann, 1953:323, est. 24, fig. 45 . Trachyderes reichei ab. reducta Tippmann, 1960:146.

Na forma típica de T. cingulatus, os élitros apresentam uma faixa amarelada transversal da margem à sutura, pouco à frente do meio, e duas manchas amareladas, apicais e suturais; a base dos fêmures amareladas, as tíbias amareladas com a base e o ápice pretos em pequena extensão. TIPPMANN (1960) descreveu a forma reducta com base em uma fêmea de Óbidos, Pará, com a banda central dos élitros reduzida a uma pequena 


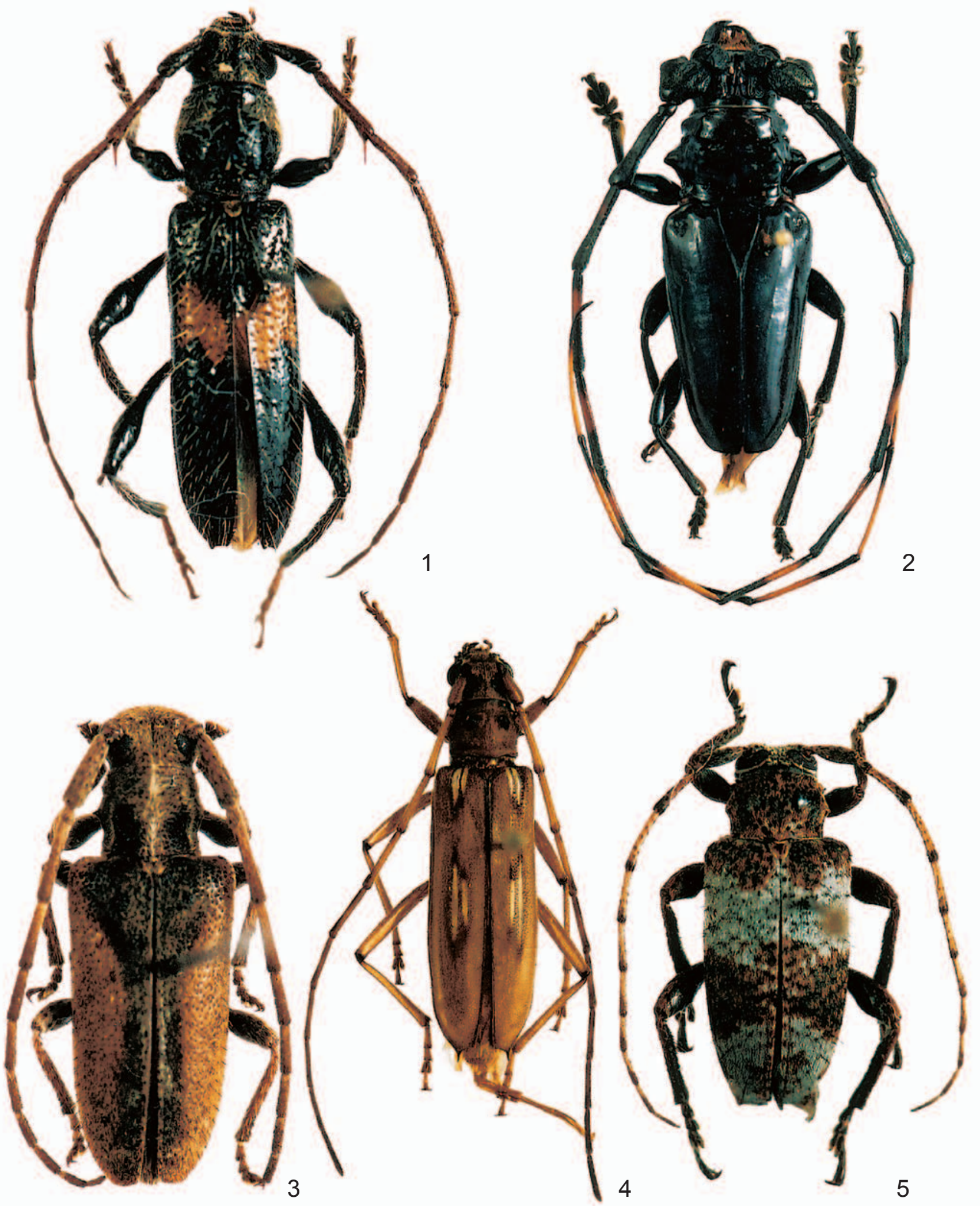

Figs. 1-5. 1, Stizocera asyka sp. nov., comprimento, 12,6 mm; 2, Trachyderes (T.) cingulatus Klug, 1825, forma melânica, comprimento, 30,6 $\mathrm{mm}$; 3, Ischnoleomimus arriagadai sp. nov., comprimento, 10,4; 4, Pantomallus titinga sp. nov., comprimento, 18,2 mm; 5, Ceiupaba bella sp. nov., comprimento, $10,4 \mathrm{~mm}$. 
mancha dorsal e sem as manchas apicais suturais.

Examinamos um macho (Fig. 2) que é uma forma melânica extrema: os élitros são castanho-avermelhados com faixa transversal preta logo atrás do escutelo e ápices pretos; os fêmures são pretos (exceto pequena área avermelhada na base dos metafêmures) e as tíbias, com exceção de anel central mais avermelhado, são pretas.

Material examinado. BRASIL, Pará: Óbidos, macho, XII.1993, sem nome do coletor (MCNZ).

Lamiinae

Desmiphorini

Ischnoleomimus arriagadai sp. nov.

(Fig. 3)

Tegumento da cabeça avermelhado revestido por pubescência densa e amarelada. Lobos oculares superiores pequenos, com cinco fileiras de omatídios, tão distantes entre si quanto o quádruplo da largura de um lobo. Antenas avermelhadas com pubescência amarelada. Escapo cilíndrico, quase atinge o meio do protórax e com o mesmo comprimento do antenômero III; franja interna de pêlos curtos, muito esparsos; pontos contrastantes moderadamente densos. Antenômeros IV-XI com comprimentos gradualmente decrescentes; o XI com aproximadamente metade do X.

Protórax apenas mais largo do que longo; meio dos lados com espinho agudo. Pronoto com duas grandes manchas escuras, uma de cada lado, da base ao meio; restante da superfície pronotal revestida por pubescência amarelada, mais clara ao longo do centro. Lados dos élitros com tegumento avermelhado; ao longo do meio, faixa de tegumento preto, mais larga na base, desde o lado interno dos úmeros e oblíqua, em sentido descendente, da margem para a sutura, até o terço anterior, de onde segue, paralela à sutura até quase o ápice. Setas pretas, curtas, em toda a superfície; pubescência unicolor, amarelada. Fêmures e tíbias com tegumento avermelhado; pontos esparsos e contrastantes. Mesotíbias com sulco raso no meio. Face ventral do corpo recoberta por pubescência branco-amarelada, entremeada por pontos contrastantes no metasterno e nos urosternitos. Mesosterno sem tubérculo.

Dimensões em mm, holótipo fêmea. Comprimento do protórax, 2,0; maior largura do protórax, 2,2; comprimento do élitro, 7,7; largura umeral, 4,0.

Holótipo fêmea procedente do PARAGUAI, Paraguari: Naranjo, coletado em 3.XI.2000 por J. Rivas (MCNZ).

Discussão. Ischnoleomimus já foi objeto de comentários por Galileo \& Martins (1996) e a presença de tubérculo no processo mesosternal, caráter que julgamos apropriado para distinguir Ischnoleomimus de Ischnolea Thomson, $1860 \mathrm{e}$ Estoloides Breuning, 1940, é variável. Esse tubérculo é muito desenvolvido em Ischnoleomimus foveatus Galileo \& Martins, 1996, menos convexo em Ischnoleomimus excavatus Breuning,
1940 e ausente nas fêmeas de Ischnoleomimus arriagadai $\mathbf{s p . ~}$ nov. Neste sexo também não é possível verificar a presença de orifícios guarnecidos por pêlos na face inferior dos metafêmures, apanágio dos machos.

O padrão de colorido, ápices elitrais arredondados e ausência de tubérculo no mesosterno distinguem Ischnoleomimus arriagadai $\mathbf{s p . ~ n o v . ~ d a s ~ d u a s ~ o u t r a s ~ e s p e ́ c i e s ~}$ do gênero.

Etimologia. O epíteto é uma homenagem a Gerardo Arriagada, pela oportunidade de estudarmos a sua coleção e em agradecimento pela doação de material-tipo.

\section{Ceiupaba bella sp. nov.}

(Fig. 5)

Corpo e apêndices com longos pêlos eretos. Cabeça recoberta por pubescência predominantemente esbranquiçada, entremeada por alguns pontos contrastantes. Lobos oculares superiores com oito fileiras de omatídios e mais próximos entre si do que a largura de um lobo. Antenas, nos dois sexos, mais longas que o corpo. Escapo avermelhado, revestido por pubescência esbranquiçada entremeada por pontos contrastantes. Flagelômeros amarelados com as pontas enegrecidas. Antenômero III mais curto do que o IV.

Pronoto com pubescência variegada de alaranjado e esbranquiçado, com predominância de alaranjado; todo pronoto com pontos contrastantes. Lados do protórax com pequeno espinho central. Élitros com faixa transversal de pubescência predominantemente alaranjada no sexto basal, interrompida em pequena extensão, atrás do escutelo, por pubescência branca; faixa branca, larga, da faixa basal ao meio; faixa transversal de pubescência predominantemente alaranjada que, especialmente nos lados, está entremeada por manchas de pubescência castanha; terço apical recoberto por pubescência branca, exceto junto da sutura, onde se encontram duas pequenas manchas de pubescência castanha circundadas por pubescência alaranjada. Estas manchas castanhas são variáveis, podem desaparecer ou apresentar maior extensão. Extremidades elitrais transversalmente truncadas com projeção larga e curta no lado externo. Fêmures com pubescência alaranjada entremeada por pubescência branca, especialmente nos lados interno e externo das clavas. Meso- e metatíbias ligeiramente engrossadas com grânulos abundantes no lado interno. Tarsômeros I e II amarelados na base. Face inferior do corpo revestida por pubescência branca; lados do metasterno e dos urosternitos com alguma pubescência alaranjada.

Dimensões em mm, respectivamente macho/fêmea. Comprimento do protórax, 2,1/2,0-2,2; maior largura do protórax, $3,2 / 3,0-3,5$; comprimento do élitro, 8,1/6,5-6,7; largura umeral, $4,4 / 3,9-4,5$.

Holótipo macho proveniente da BOLÍVIA, La Paz: Uyapi (Huanoy), coligido em X.1993 (sem nome do coletor) (MCNZ). Parátipos: EQUADOR, Pichincha: Santo Domingo (1000-1500 m), fêmea, V.2001, S. Castro-Martínez col. (MZSP).GUIANA FRANCESA, Korou (Montagne des Singes), fêmea, 18.I.1983, M. Duranton col,. armadilha luminosa (MNRJ); Saul (Mont. La Fumée), fêmea, 10.V.1983, F. Lambert col., armadilha luminosa (MNHN). 

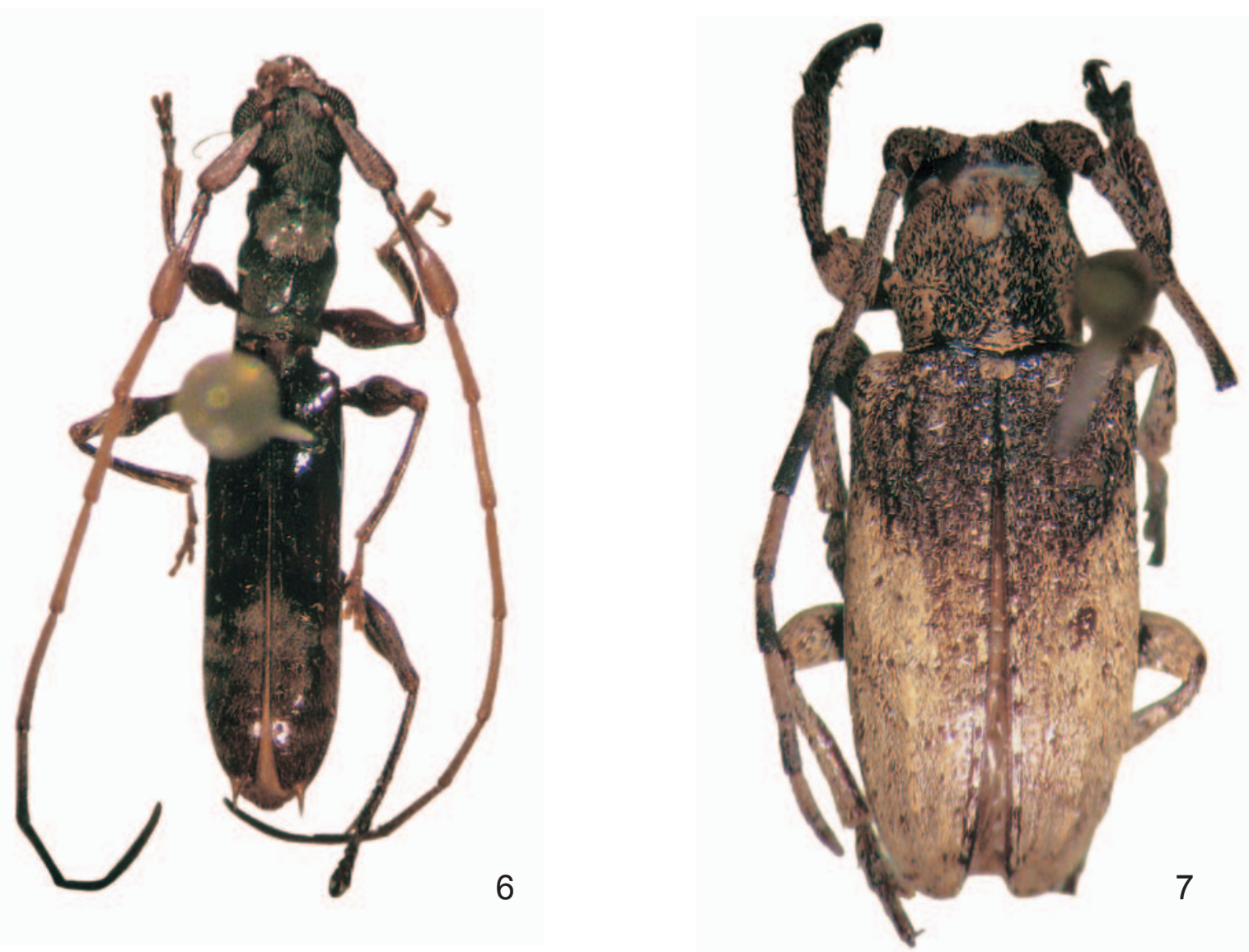

Figs. 6-7. 6, Cycnidolon immaculatum sp. nov., comprimento, $8,0 \mathrm{~mm}$; 7, Euestola obliqua sp. nov., comprimento, 7,0 mm.

Discussão. Ceiupaba bella sp. nov. assemelha-se à $C$. capixaba Martins \& Galileo, 1998, pela ausência de orifício arredondado no lado inferior da clava dos metafêmures e pelo padrão do colorido dos élitros. Além de ocorrer em formação vegetal diferente, $C$. bella distingue-se de C. capixaba pelo protórax revestido por pubescência predominantemente alaranjada com abundantes pontos contrastantes; pelos lados do protórax com tubérculo mais evidente; pelo padrão de colorido dos élitros, pelas extremidades elitrais transversalmente truncadas com projeção no ângulo externo. Em C. capixaba, o pronoto é revestido por pubescência uniforme branco-amarelada com poucos pontos contrastantes; o protórax é desarmado aos lados ou possui tubérculo muito pequeno; o padrão de colorido dos élitros, representado em MARTINS \& GALILEO (1998: 262, fig. 6) e pelas extremidades elitrais arredondadas.

\section{Euestola obliqua sp. nov.}

(Fig. 7)

Cabeça com tegumento castanho, revestida por pubescência amarelo-esbranquiçada. Antenômeros VI, VIII e $\mathrm{X}$ com tegumento amarelado, escurecidos em pequena porção apical. Escapo e flagelômeros basais revestidos por pubescência amarelo-esbranquiçada. Protórax revestido pela mesma pubescência escamiforme (32x). Pronoto convexo, com pubescência mais esparsa que permite ver a pontuação muito densa. Élitros praticamente sem pubescência no terço anterior e com densa pubescência amarelo-esbranquiçada nos dois terços apicais; limite, entre a parte mais glabra e a parte pubescente, oblíquo em sentido descendente da margem para a sutura. Élitros aplanados no dorso do terço anterior; presença de crista centro-basal, pouco elevada, encimada por pontos tuberculiformes (bem visíveis em vista lateral). Face ventral revestida por pubescência amarelo-esbranquiçada.

Dimensões em mm, macho. Comprimento do protórax, 1,6; maior largura do protórax, 1,9; comprimento do élitro, 4,8; largura umeral, 2,6.

Holótipo macho proveniente do PARAGUAI, Caazapá: Estero Cristal, coletado em 1-22.XI.1998 por J. Jensen col. (MZSP).

Discussão. O gênero Euestola foi revisto por MARTins \& Galileo (1997). Na chave para as espécies, Euestola obliqua sp. nov. assemelha-se à $E$. lineata Martins \& Galileo, 1997 e $E$. basalis Martins \& Galileo, 1997, respectivamente, ilustradas nas figuras $6 \mathrm{e} 7$. O aspecto geral, entretanto, é mais semelhante ao de E. basidensepunctata Breuning, 1943, representada na 
figura 5. Euestola obliqua difere pelo antenômero IV com tegumento unicolor; pelo protórax sem gibosidade centrobasal; pelo limite entre a área glabra da base dos élitros e a área pubescente, oblíquo em sentido descendente da margem para a sutura e pela ausência da faixa central de pubescência branca nos élitros.

Agradecimentos. A Gerardo Arriagada por ceder o material da sua coleção para o MCNZ e o MZSP; a Antonio Santos Silva (MZSP) e Luciano de A. Moura (MCNZ) pela execução das fotografias.

\section{REFERÊNCIAS}

Dupont, H. 1836. Monographie des trachydérides. Magazin de Zoologie 6: $1-51$.

Galileo, M. H. M. \& U. R. Martins. 1996. Notas e descrições em Desmiphorini (Coleoptera, Cerambycidae, Lamiinae), com uma revisão do gênero Mimasyngenes Breuning. Revista Brasileira de Zoologia 13(4): 867-882.

KLUG, J. C. F. 1825. Entomologiae Brasilianae specimen alterum, sistens insectorum coleopterorum nondum descriptorum centuriam. Nova Acta Academiae Caesareae Leopoldino-Caroline germanicae naturae curiosorum 12(2): 421-476.

Martins, U. R. 1999. Cerambycidae Sul-americanos (Coleoptera). São Paulo, Sociedade Brasileira de Entomologia. v. 3, 418 p.

Martins, U. R. \& M. H. M. Galileo. 1997. Revisão dos genêros Pseudestola Breuning, Estolomimus Breuning e Euestola Breuning (Coleoptera, Cerambycidae, Lamiinae, Desmiphorini). Revista Brasileira de Zoologia 14(1): 99-112.

Martins, U. R. \& M. H. M. Galileo. 1998. Generos sul-americanos de Desmiphorini (Coleoptera, Cerambycidae) com lados do protórax desarmados. Revista Brasileira de Entomologia 41(2-4): 257 265.

Martins, U. R. \& M. H. M. Galileo. 2002. Cerambycidae (Coleoptera) da Colômbia. I. Eburiini (Cerambycinae). Iheringia, Série Zoologia 92(4): $5-10$

Martins, U. R. \& D. S. Napp. 1983. Gêneros Stizocera Audinet Serville, Nesostizocera Linsley e Parastizocera Linsley: chaves para espécies, descrições, notas e sinonímias. Papéis Avulsos de Zoologia 35(7): 79-92.

Monné, M. A. 1994. Catalogue of the Cerambycidae (Coleoptera) of the Western Hemisphere. Part XI. São Paulo, Sociedade Brasileira de Entomologia, 157 p.

Tippmann, F. F. 1953. Studien über neotropische Longicornier II. Dusenia 4: 313-362.

Tippmann, F. F. 1960. Studien über neotropische Longicornier III. Koleopterologische Rundschau 37-38: 82-217. 